\title{
O espaço social e o tempo histórico na era global: entre dinâmicas culturais inclusivas e excludentes
}

\author{
El espacio social y el tiempo histórico en la era mundial: entre \\ dinámicas culturales inclusivas y excluyentes
}

\section{Social space and historical time in the global era: between inclusive and excluding cultural dynamics}

\author{
James Washington Alves dos Santos ${ }^{1}$
}

\begin{abstract}
Resumo
Este artigo buscou estudar com base em pesquisa bibliográfica os conceitos de espaço social e tempo histórico trazendo para o debate a contribuição de diversos autores das Ciências Humanas. No nosso objetivo é problematizar temas como: espaço social, tempo histórico, globalização, cosmopolitismo, populismo e xenofobia, elementos que nos ajudam a entender a crise da pertença e das origens. Na medida em que o tribalismo aumenta, reforça a existência de Estados murados na tentativa de manter uma soberania em declínio. Os ideais da luta de classes enquanto uma história política e filosófica perdem sentido e o ser humano se atomiza cada vez mais. Estes sinais para Domenico Losurdo e F. V. Paleólogo revelam a emergência de um direito social sob sequestro. Assim, fomos da emergência humanitária ao estado de exceção, como disse S. Sassen, gerando migrações massivas a Europa, pulsões, brutalidade e complexidade na economia global. São os tempos dos muros caídos (fronteiras) e dos muros erguidos (desigualdades).
\end{abstract}

Palavras-Chave: espaço social, tempo histórico, globalização, populismo, xenofobia.

\section{Resumen}

Este artículo buscó estudiar con base en investigación bibliográfica los conceptos de espacio social y tiempo histórico trayendo para el debate la contribución de diversos autores de las Ciencias Humanas. En nuestro objetivo es problematizar temas como: espacio social, tiempo histórico, globalización y cosmopolitismo, populismo y xenofobia, elementos que generan nos ayudan a entender la crisis de la pertenencia y de los orígenes. En la medida en que el tribalismo aumenta, refuerza la existencia de Estados amurallados en el intento de mantener una soberanía en declive. Los ideales de la lucha de clases mientras una historia política y filosófica pierden sentido y el ser humano se atomiza cada vez más. Estas señales para Domenico Losurdo y F. $V$. Paleólogo revelan la emergencia de un derecho social bajo secuestro. Así, fuimos de la emergencia humanitaria al estado de excepción, como dijo S. Sassen, generando migraciones masivas a Europa, pulsiones, brutalidad y complejidad en la economía global. Son los tiempos de los muros caídos (fronteras) y de los muros erguidos (desigualdades).

Palabras clave: espacio social, tiempo histórico, globalización, populismo, xenofobia.

\section{Abstract}

This article sought to study, based on bibliographic research, the concepts of social space and historical time, bringing to the debate the contribution of several authors of the Human Sciences. In our objective is to

\footnotetext{
${ }^{1}$ Professor do Instituto Federal - Alagoas (IF-AL) e aluno de doutorado em Ciências Sociais pela UNESP; Araraquara, São Paulo, Brasil; james.was@hotmail.com. Trabalho apresentado no I Seminário LatinoAmericano de Estudos em Cultura - SEMLACult, Foz do Iguaçu/PR, Brasil, 2017.
} 
problematize themes such as: social space, historical time, globalization and cosmopolitanism, populism and xenophobia, elements that generate help us understand the crisis of belonging and origins. As tribalism increases, it reinforces the existence of walled states in an attempt to maintain declining sovereignty. The ideals of the class struggle as a political and philosophical history lose meaning and the human being becomes more and more atomized. These signs for Domenico Losurdo and F. Palaeologus reveal the emergence of a social right under abduction. So we went from the humanitarian emergency to the state of exception, as $S$. Sassen said, generating massive migrations to Europe, drives, brutality and complexity in the global economy. These are the times of fallen walls (frontiers) and erected walls (inequalities).

Keywords: social space, historical time, globalization, populism, xenophobia

\section{O espaço social e o tempo histórico}

A partir de década de 1970, os conceitos de Estado Nação e Estado Social sofrem a sua mais grave perca de sentido e configuração. A defesa de novos valores baseados num posicionamento anti-estatal e anti-fiscal disseminaram a crença na ineficiência do Estado em contraposição à emergência eficaz de um mercado hábil e criativo.

O que sobra ao Estado é uma batalha cultural cuja ideologia que domina é a identificação deste com as definições de despótico e totalitário. Neste sentido, perde-se a identidade de um Estado que tem atrelado a si os cidadãos, reduzidos agora a condição de indivíduos, com sérias limitações de vínculos de pertença e responsabilidade.

Disso resultam duas rupturas fundamentais e nocivas: a do espaço, mostrando que o habitar, o educar e o trabalhar já não estão associados a um lugar de vinculação pessoal. Criando então o que Marc Augé (2005) chamava de um não lugar. Com as fronteiras e os espaços abertos a circulação, as necessidades financeiras e de trabalho superam as necessidades de ligação sujeito/espaço social e assim as redes de relações se alongam e as solidariedades se esvaem. E a ruptura do tempo, que por sua vez provoca a impossibilidade de um diálogo intergeracional. As gerações mais antigas se colocam diante de diálogos cada vez mais tensos com as gerações mais novas, que por sua vez não estabelecem vínculos com a trajetória familiar e as próprias histórias de vida de atomizam, restando apenas os vínculos biológicos e jurídicos como os mais fortes. Assim a relação: gerações/trabalho/vida se montam de maneira mecânica sem produzir maior nível de solidariedade.

Estas rupturas no espaço e no tempo surgiram com o argumento de que o movimento da história e suas modificações se contrapõe a estática de uma vida sem progresso. Isso leva a uma "modernização" do capitalismo e consequentemente das relações sociais que o circulam. O progresso se instaura então como discurso que reivindica ao Estado um controle e manipulação não pelo uso da força, mas pelo controle da vida e da sociedade enquanto acesso aos direitos. Como este acesso só se cristalizou em um prazo curto de tempo (o estado de bem 
estar-social do pós II Guerra Mundial), houve então uma desqualificação do Estado e sua substituição pela economia, resultando na perca do seu papel formativo e cultural.

O Estado passa agora de positivo (revolucionário), para ser um elemento repressivo (agrupamento bélico). O interregno, ou seja, o espaço que o Estado deixa livre na medida em que as políticas sociais não se consolidam enquanto programa, permite o surgimento do pensamento anti-estatal, que logo monta seus dois movimentos ideológicos nos anos 70:
a) Pós-Modernismo: que coloca em xeque o Estado;
b) Revisionismo Histórico: que deslegitima o processo da modernidade.

Assim na segunda metade do século XX a noção de indivíduo ganha força, o poder do Estado se confina nos regimes totalitários de controle e o capitalismo enquanto sistema se fortalece. Assim se consolida o fim da belle époque ou belle époque da globalização.

a) 1870-1914: Cidadãos do mundo, próspero e com crescimento;

b) 1989-1991: Fim do comunismo e a abertura dos mercados de maneira global.

Isso gera reflexos de dois tipos nas dinâmicas culturais: um inclusivo, que dentro do território vai exaltar o particular (negação do diverso, outro, migrante). Tendo como base uma forma específica de urbanização e mostra separação do multiculturalismo. E um excludente que fomenta retiradas dos direitos sociais e econômicos com esvaziamentos de diretos e criação de espaços de exceção.

As dimensões das mudanças nas concepções de espaço e tempo histórico são radicais e profundas. No "mundo da vida", uma alteração nas formas de sensibilidade, sentidos, intelecto, entendimento, percepção e compreensão. No "mundo social e político": instituições, organizações, estruturas sociais e associações perdem sentido.

Forças e potências políticas e sociais não possuem mais o poder e prestígio que outrora possuíam. Assim se produz uma sociedade democrática apenas formalmente, mas não substancialmente. O capital enquanto força produziu o fim da memória e o empobrecimento cultural e político na maioria da população. Soma-se a isso a perda de segurança e proteção sociais bem como o seu sistema de garantias como: saúde, emprego, previdência, educação, mobilidade, justiça social e moradia. Para fechar o quadro temos o fim do Estado Nação que consigo leva a formação de um senso comum com suas obrigações, sacrifícios, renúncias, 
regras e limites para as ações. Cai ao mesmo tempo a coesão social, o senso da vida e a comunidade nacional de destino.

Diante de todos esses pontos, a partir de 1980, o capital realiza uma fuga pela desindustrialização por meio da mudança de mercado e a desurbanização, com a saída de trabalhadores de bairros antes habitados por causa dos meios de renda que ali existiam. A base para o funcionamento desta lógica é a criação de uma política do medo: irredutível, emergencial (fluxo de migração e competição) e reformista (esvaziamento do estado social). É uma fórmula chamada de revolução espacial radical. É uma mudança de sentidos: modificação/ampliação que tem por base a conquista, divisão e organização de um território. Desta forma há uma modificação e ampliação do poder (que em cada época se especifica em força, potência e hegemonia) e hoje está alicerçada em corporações transnacionais com sua constituição moral, princípios e valores próprios.

\section{O espaço social e suas dimensões}

As dimensões das mudanças no que se refere ao espaço social podem ser consideradas radicais e profundas. No "mundo da vida" houveram mudanças de sensibilidade, sentido, intelecto, entendimento, percepção e compreensão. Como também em instituições, organizações, estruturas sociais e associações.

Segundo, Karl Schmitt (2008), temos uma nova revolução espacial radical relacionada com forças econômicas e políticas. A saber, a mundialização do capital com seu deslocamento e a globalização com sua capacidade de promover mudanças econômicas e políticas. Com isso há uma mudança dos sentidos, modificando e ampliando o poder do nomos (regras sociais que em cada época se especifica em força, potência e hegemonia). Para Gustav Le Bom (2016) se utilizar de termos como nomos para explicar as dinâmicas sociais é usar a força das palavras na história, algo movido pela manipulação das imagens, força da liderança e pela fé das pessoas no carisma de outrem. Com isso é possível dizer que a liderança cria vínculos. Mastropaolo (2014) argumenta que estes são aspectos da democracia, que é uma invenção humana e que há um privilégio na promoção dos direitos de liberdade sobre os direitos sociais.

A cidade moderna teria então seu fim a partir da década de 1980, período concebido de início como o espaço de liberdade, associação, fé e criação no comércio, arte, ciência e técnica. O que tínhamos antes era o espaço de igualdade de direitos, por gerar relacionamentos intersubjetivos comuns, identidade comum e no meio público formavan-se 
vínculos, ligações entre diversas formas de vida (consenso unitário), formando o destino da sociedade, da nação e do Estado moderno. No entanto as causas da dissolução deste período seriam o declínio da política, enquanto agente regulador de economia, gerando um esvaziamento da dimensão coletiva do senso da realidade social e da ideia de vida cívica (moralidade existente na sociedade civil, economia de mercado), elementos que deveriam ser elevados à condição ética (eticidade).

Por eticidade entendemos a gramática que contém o reconhecimento de valores específicos, gerando novos valores gerais (universais). Assim os conflitos são resolvidos em sua dimensão contraditória gerando superação enquanto processo de conservação (daquilo que perdeu o grau de violência, brutalidade) e será sublimado, elevado ao progresso moral coletivo e político. (GREGOTTI, 2011). O progresso material e imaterial (valores, normas e leis) geraria o aperfeiçoamento da vida particular, do ser autônomo, autoconstrutor e junto a isso viria o aperfeiçoamento da vida coletiva, a universalidade do concreto, a igualdade e a liberdade.

De outro lado temos também as questões de Mutabilidade. A identidade não é mais o resultado de um processo coletivo, inclusivo e igualitário sendo então o resultado de um processo cultural, econômico e político que gerou a fragmentação das forças sociais e da “comunidade nacional de destino". Houve uma inflação das subjetividades e particularidades e junto com isso fenômeno do tribalismo, das diferenças e da quebra do civismo no Estado Nação.

Novas questões urbanas então apareceram. O Urbanismo privado chega como algo virtuoso (o ser humano cria sua relação com o espaço, com sua vontade subjetiva, minoritária e empreendedora de sucesso) e aparece com vigor a separação do espaço (cidade dos ricos/cidade dos pobres). O urbanismo de fixa como potência de forças econômicas, gerando projetos não modernos, a-históricos. Os projetos agora expressam a grandeza e a força de seus agentes. Isso se reflete diretamente na ideia de cidade contemporânea que gera novos conflitos e contradições como: a mundialização dos capitais e a globalização, os fluxos migratórios e o problema demográfico (qualitativo e quantitativo), constituindo-se enquanto problema politico que abre espaço para o discurso da extrema direita.

Apesar da modernidade empreender um progresso técnico, material e civilizatório, não há o acompanhamento do progresso moral ("miséria brilhante" segundo Immanuel Kant). O poder material se oculta na miséria como algo brilhante e a miséria desta forma torna-se a persistência da desigualdade, justificada pela submissão, dominação e exploração que só se pode superar pelo processo de moralidade. 
É por isso que o uso da percepção das angustias, medos, incertezas e inseguranças acaba sendo um recurso a ser explorado. Há então uma queda do nível de vida material: precário, insuficiente em relação a consumo de bens, saúde, educação, lazer e turismo, bem como a mudança dos modos de vida: mudança de valores e identidade coletiva (REYNIÉ, 2013). Isso gerou, segundo Jean Raspail (1973) problemas migratórios no que ele denomina de "campo dos santos", ou seja, uma invasão dos pobres e miseráveis ao ocidente, o que acaba por gerar uma política de tolerância zero, o que Luigi Ferrajoli (2011; 2013) chama de populismo penal, repressivo, violento e racista, de criminalização eletiva e fraca com os fortes.

S. Sassen $(2013 ; 2014)$ argumenta que a cidade abriga os mais complexos conflitos e problemas de identidade política (questões de direitos humanos e os processos de negação de direitos). Isso cria um húmus cultural e político particularista e suscita questões nacionais: exclusões, negação de direitos, do trabalho e da política, criando ainda a fragmentação da vida social e o enfraquecimento da etinicidade e dos valores comuns e universais.

Na cidade contemporânea o ser humano constrói sua subjetividade (formação de figuras), o que representa para este uma forma de vida e de base axiológica dos valores. Estar no mundo é gerar uma mentalidade, um comportamento, uma orientação, um sentido e um significado. No entanto, como a criação da figura do empresário, empreendedor de si mesmo, que rompe com os vínculos sociais por meio do sucesso, das questões habituais e da solidão pessoal, migramos para a tendência em privilegiar a expansão do capital particular e o emprego da alta performance. Privilegiou-se a diferenciação: espaço privado/espaço público, com um ser atomizado e meritocrático, com possibilidade de acúmulo de renda e bens ilimitada. O seu sentido agora é a busca por prestígio e poder sendo a sua finalidade particular e privada.

Haverá em meio a estas circunstâncias o medo da presença do outro, que se intensifica na medida em que os transportes melhoram e o deslocamento passa a ser uma ameaça constante. Para amenizar este impacto vem o surgimento de políticas securitárias, discriminatórias e racistas, o que Zigmunt Bauman (2005; 2008) chama de "mixofobia" e Máximo Recalcati (2015) de "retorno aos mitos", ou seja, as origens, aos modos de vida ditos verdadeiros e ligados aos antepassados como negação do multiculturalismo.

\section{Cosmopolitismo, populismo e liberdade privada como dinâmicas excludentes do capitalismo}


Com o surgimento do cristianismo e da ideia de um só Deus (monoteísmo e religião da palavra) a ordem do cosmos estava colocada como em perfeita harmonia e hierarquia que organiza e ordena as diversas ontologias em suas identidades, papéis e funções (lugar natural). Cada coisa e cada ser teriam o seu lugar, na medida em que o movimento não-natural produziria uma degeneração e corrupção (imobilismo).

O cosmos é desordenado pela queda (corrupção do homem e da mulher). Isso muda o senso da história. Joaquim de Fiori e Agostinho produzem um pensamento teológico que evidencia esta queda, mas ao mesmo tempo enfatizam que a "mortificação" do corpo gera purificação e santificação da alma. Esta seria então a tentativa de formar uma "República Universal Cristã”, buscando a reconciliação dos homens entre si e dos homens para com Deus (fim do pecado e dos conflitos).

Com o advento da Modernidade, a Filosofia, agora laicizada, mundana e voltada para a economia e a política (mercado e agentes produtivos autônomos indispensáveis) faz emergir uma vontade eletiva capaz de gerar valores diversos e identidades particulares com vista a interesses próprios. A economia de mercado produz novas dinâmicas, novos processos de produção, valorização e também novos conflitos e contradições. No território nacional, temos a luta de classes latente e explosiva. O conflito acerca das capacidades põe em ordem uma sociedade que reivindica a determinação do senso da história. Agora o sentido é teleológico (com fim mundano), histórico, econômico e político. Assim pelo poder e pela coerção, existem conflitos e contradições. Na era moderna e na modernidade os movimentos e as ações, relações e novas estruturas que dão ordem a sociedade acabam por gerar uma série de catástrofes. Algo eminentemente de origem humana. Neste sentido Hegel (2008) já dizia que o que move a história são as tragédias.

Por sua vez, Immanuel Kant afirma em: A paz perpétua (2008), que a principal obra humana é a razão, operada pelo Direito Civil através de valores e normas; pelo Direito Internacional, através do comércio e dos Estados colonialistas e o Direito Cosmopolita, através do indivíduo, da pessoa, do sujeito e do cidadão.

Estes feitos se potencializam de fato a partir de 1980 quando tivemos o deslocamento de capitais: o capital é o principal agente/força que gerou a cosmopolitização. Sua hegemonia é capaz de construir em todos os espaços as interdependências, troca de mercadorias, produção de mercadorias, produção de valorização. Ao mesmo tempo que pode trazer consigo a presença do diverso: em valores, interesses, identidades e perfis de consumo. Ulrick Beck (2011; 2013) argumenta que este diverso está presente no território nacional. Existe então uma cosmopolitização ordinária ou seja a pessoa física como portadora de valores e coisas. 
Hoje a cosmopolitização não é nem religiosa nem filosófica. É factual. Isso por causa o deslocamento de capitais (década de 1980). É também inaudita pela alteridade de valores que estão inseridos em nossa vida. Ulrich Beck (2003, 2005, 2011(b)) analisa este fenômeno como cosmopolitização de baixo, ordinária, afetada profundamente pela globalização econômica e política (o neoliberalismo), criando assim novas formas de vestimentas, valores, identidades, particularidades e relações intersubjetivas.

Nos novos espaços, o outro faz parte do local, do regional, do nacional de forma permanente. Este jogo de forças do cosmopolitismo gera questões ligadas a identidade, consumo, valores locais, nacionais, regionais e modos de produção (relações capital/trabalho). Gera também a desnacionalização. Assim a política não é capaz de controlar as forças econômicas (espírito animal do capitalismo) que provoca as migrações em massa, dificultando também a construção coletiva do senso de realidade, coesa, responsável, coerente e voltada para a comunidade nacional de destino. Com isso, após a guerra fria 1945-1989-91, tem-se visto o resultado de uma batalha cultural que define as virtudes de um mundo livre, porém efetuando políticas de segurança (contra a invasão) e políticas de imunização (contra o contágio do outro).

Como forma de proteção a estas invasões, o populismo agrega forças de ideias. Seus slogans mexem com as forças produtivas, gerando uma política do medo e são empreendedoras do medo. Esta nova ideologia gera a perda na força das palavras transferindo a percepção para as imagens (cinema, TV e rede/internet). Isso atinge a sensibilidade e os sentidos são bombardeados por imagens provocando o esvaziamento das capacidades narrativas (aptidões). O outro ponto é o esvaziamento da experiência, que atinge as vivências e como os objetos são percebidos.

O populismo atua então como uma reação ao establishment, com lutas sociais e políticas por reconhecimento e respeito. Busca por emancipações, estabelecimento de direitos humanos fundamentais (1948) e por uma economia e política que privilegiem o indivíduo, a pessoa, que resultem em garantias e segurança material, autonomia, liberdade e igualdade. É também uma atitude de anti-pluralismo diante de diversas formas de vida e de individualização das moralidades, gerando maiores conflitos, tensões e contradições. É uma atitude anti-elites e anti-intelectual. As elites intelectuais, econômicas e politicas se tornam perniciosas, prevaricantes. Também nega a importância das instituições intermediárias e da democracia representativa promovendo a perda de referência de partidos e sindicatos, bem como os conflitos de classe, enfraquecendo a dialética da revolução. Isso gera a artificialidade das representações por meio do uso de tecnologia para dar a sensação de participação popular. 
Além disso, reivindica o monopólio da representação popular estreitando a relação líder/povo e o monopólio da moral não relativizada.

A linguagem política dos discursos populistas está ligado a extrema direita e junta-se a mecanismos e dispositivos da política do medo para fazer acontecer a emergência fantástica de dinâmicas sociais, normas e leis. Autores como J. L. Amselle (2014) argumentam sobre a emergência dos "novos vermelhos" (marrons), evidenciando o racismo que está por vir; P. Basso (2011) mostra a questão do racismo de Estado nos Estados Unidos, Europa, Itália; A. Burgio (2010) coloca que não obstante Auschwitz estamos diante do "retorno" do racismo na Europa; W. Brown (2015) enfatiza o esfacelamento da ideia de demos (do povo enquanto elemento construtivo e participativo); A. Rivera (2003) coloca o problema dos estrangeiros como inimigos; Tz. Todorov (2012) identifica os inimigos íntimos da democracia; N. Urbinati (2014) mostra as desfigurações do processo democrático nas formas de opinião, verdade e povo e G. Zagrebelsky (2010), problematiza a questão da língua do tempo presente e nos lembra que a palavra e a imagem legitimam mudanças, tendo a palavra implicações culturais, políticas e econômicas.

O discurso populista vai usar o estilo retórico que identifica o povo como portador de sabedorias e virtudes inatas para contrapor o povo ás elites (cosmopolitas, corruptas, degeneradas e aproveitadoras, vivendo á custa do povo). Povo teria aqui uma origem pura, como pessoas simples-laboriosas, moralmente boas. Assim o anti-intelectualismo identificará as elites como inúteis, prevaricadoras, incapazes, negando a força da democracia representativa-parlamentar e afirmando a democracia direta e o plebiscito como a verdadeira democracia. Sendo a vontade da maioria do povo que deve ser soberana e sem mediações políticas (LE BOM, 2016).

A figura do líder será identificada como membro do povo, que ouve, interpreta e realiza as mudanças profundas na sociedade nação (global). D. Raynié (2013) diz que esta é a tônica dos novos populismos. Exploram a questão identitária, bem como a insegurança identitária (promovendo o nacionalismo e a contraposição a diversidade/pluralidade). Desafiam assim questões como: globalização, demografia e imigração, criando por outro lado um populismo patronal de concepção etinicista, com conotações de populismo material, que busca a melhoria do nível de vida e de populismo imaterial, exaltando um modo de vida próprio, particular.

Com a desestabilização patrimonial (material e imaterial), se gera a demanda por segurança e proteção para os verdadeiros cidadãos na medida em que a negação na democracia moderna do Estado Social, dos direitos humanos fundamentais, do 
multiculturalismo e do universalismo se fazem presentes. Esta seria uma mentalidade que considera o povo como uma totalidade orgânica, que foi artificialmente dividida pela ação de forças hostis. Esta ênfase no povo e no ethos que possuem qualidades inatas, toca no modo de sentir, pensar e agir mais emotivo do que racional, que reage ás situações segundo as necessidades e os interesses momentâneos, sem a força de uma ideologia forte e monolítica: valores genéricos e pragmáticos.

É possível então definir este mesmo populismo como elemento que desqualifica e nega a importância das instituições intermediárias da democracia representativa: sindicatos e partidos, reivindicando para si o monopólio da representação popular, além do monopólio da moral. Exalta o povo como sendo uno, homogêneo, autêntico, moralmente puro, trabalhador e sábio e exalta a figura do líder como a representação única e absoluta do povo, que deve ter um mandato imperativo e sem limites restaurando na sociedade a ordem (o "lugar material", originário, não artificial).

Mastropaolo (2014) comenta que no final dos nos 70 no Norte da Europa o partido do povo (Partidos da Liberdade), teceu duras críticas contra o Estado Social. Primeiro argumentando uma posição anti-fiscal e anti-estatal contra a grandeza do Estado, colocando que isto resultaria num peso insuportável. Como proposição sugeriram a diminuição do papel do Estado na economia e na sociedade (Estado mínimo e privatizações). Com isso os novos atores políticos: movimentos sociais e partidos políticos passaram a não possuir raízes na memória histórica e política moderna, junto a isso veia a promoção de uma identidade étnica e cultural que tomou a direção para o uno: língua, cultura-tradição, religião e economia.

Consolida-se desta forma a fé no ser humano - criativo, inventivo, conhecedor e dominador da natureza; na ciência técnica, produzindo a figura do ser humano; no ser demiurgo: progressos gerariam uma sociedade mais abundante em recursos (retirando da vida o flagelo da fome, das doenças e das guerras). Assim a educação racional geraria o ser dotado de maior conhecimento, adestrado (racionalidade que elimina a irracionalidade, a brutalidade, gerando um homem novo plenamente racional e sensato). Isso tem seu desfecho na construção da sociedade perfeita.

Stefan Zweig (2014) fala sobre "o mundo de ontem" ao mostrar que o continente europeu vive em gigantesca transformação. Com isso surgem medos e problemas em face ao cheiro de novas configurações ligadas a hibrys da natureza: seca, chuva, temperatura, terremotos, tsunamis, bem como as ligadas a hibrys do poder: ambições, reis, príncipes, aristocratas, governos, mobilização total, guerras de exceção, recursos, domínio e terror. 
Ajudando a entender este mundo de hoje, J. M. Keynes (2010) argumenta que o inevitável não acontece nunca, o imprevisto sempre. Falando assim de fatos e acontecimentos que não são plenamente visíveis, mas se apresentam, como o que ocorreu nos anos 80 com o início nas privatizações, esvaziamentos do papel do Estado, controle pelo capital da economia política, regulamentação de limites para o processo de valorização do trabalho, compromissos e acordos, concentração de riquezas e distribuições, declínio do público, de empresas e pessoas.

\section{A liberdade privada e suas raízes xenofóbicas}

Segundo Vitor Hugo “o futuro é a grande questão! De que O amanhã será feito?”. Para esta pergunta temos as resposta de Remo Bodei (2013), afirmando que é possível imaginar outras vidas, gerações e limites para além do que é posto. Para Carlo Galli (2010) existem espaços políticos a serem trabalhados ainda que diante de uma guerra global. Já para Salvatore Natoli (2010), o precisa ser definido é o bom uso do mundo em meio a uma era de risco. Contudo, o que domina para Mássimo Recalcati (2015) é a força do desejo individualizado.

Chiara Saraceno (2012) argumenta também que até o discurso sobre os casais e as famílias saíram do terreno da questão natural, gerando efeitos positivos e negativos. Nos positivos a pluralidade das formas de vida em sociedade e do lado negativo as tentativas de fechar e destruir formas de existência do novo. Deste modo a Modernidade "sólida" foi então dissolvida no espaço e no tempo diante de novos arranjos familiares, bem como na dissolução do mundo do trabalho: "o trabalho seguro não há mais". Em âmbito privado a casa não é mais ponto da tradição, persistindo diferenças de visão entre gerações. Para Ulrick Beck (2005) o que resta é a nacionalização (ou formação do uno), criando dispositivos para a imposição de uma lógica da nacionalidade que se contrapõe a diversidade.

No final dos anos 80 foi então liberada uma potência externa da ideologia neoliberal, capaz de resignificar toda a realidade física e cultural.
a) Poder de transformar as coisas em mercadorias;
b) processo de valorização;
c) transformação de tudo em capital;
d) novo senso das instituições privadas e públicas. 
Estes elementos junto com a ausência de orientação geram uma voracidade do narcisismo e do hedonismo. Surgem assim novas inseguranças, angústias e medos. Freud assim falava em três problemas: o desejo de retorno à horda primitiva, as pulsões da morte e o narcisismo coletivo. Desenvolveu-se um eu livre, capaz de formar uma espécie de homo economicus (inventivo, criativo, capaz de controlar emoções e sentimentos, de produzir uma mentalidade da escolha racional, eficaz, eficiente como gestora, empreendedora de si mesma), permanente em expandir ilimitadamente a subjetividade.

Junto a este homo economicus está um capital móvel que desloca vontades (afirmando a independência em relação ao Estado nacional e a classe trabalhadora nacional). Acompanham também a revolução técnica e as mudanças nas determinações sobre o senso da história e da ordem. Os diques metafísicos e religiosos perdem sua potência e o eu flui num mundo de incessantes transformações. Não há mais nenhuma interioridade. A liberdade privada gera uma separação, um desenraizamento, uma desorientação, uma atomização, uma insegurança e uma incerteza espiritual. Se indivíduo então se torna autoresponsável por si mesmo, as diferentes identidades se afastam da política tentando criar um consenso que se afasta de uma política plural dificultando o reconhecimento recíproco.

A realidade mostra então o ponto onde as forças sociais e políticas se posicionam. Daí surgem fenômenos sociais inauditos (antes não vistos), como o progresso tecnológico concomitante a pobreza e as desigualdades e a desvalorização da sociedade e do Estado (que põe em cheque a Social Democracia Moderna e o Estado Nação). Estamos em uma passagem de época. Passamos da ideia de comum, social e universal (universalismos) para uma sociedade fragmentada.

Outro fenômeno importante a ser analisado é o tribalismo. Ele se apresenta como ethos cultural (no plano nacional e político). Na democracia moderna está ligado ao trabalho como valor pessoal destituído do trabalho enquanto valor social. Assim transforma trabalho concreto em abstrato (desregulamentado), gerando um individuo sem identidade coletiva nacional, sem solidariedade nem reconhecimento recíproco, sem vínculos e segurança.

Existe uma proliferação de crises, crises pertinentes e devastadoras em seus efeitos, porém o desvendar da verdade é o resultado de um duro e árduo processo de reflexão. A força do logos busca então dominar, seduzir e manipular as formas de vida: Subjetividade/Objetividade. Seguindo as ideias de Karl Marx (2013) e Domenico Losurdo (2013), no capitalismo contemporâneo a força hegemônica que determina e controla o modo de produção, determina e controla o sentido, a criação das palavras, imagens e emoções. 
As vezes me parece que uma epidemia pestilenta atingiu a humanidade inteira em sua faculdade mais característica, ou seja, no uso da palavra, constituindo essa peste da linguagem numa perda de força congnocitiva e de imeadiaticidade, como um automatismo que tendesse a nivelar em fórmulas mais genéricas, anônimas, abstratas e diluir os significados, a embotar os pontos expressivos, as extinguir toda a centelha que crepite no encontro das palavras com novas circunstancias(...). Gostaria de acrescentar não ser apenas a linguagem que me parece atingida por essa pestilência. As imagens, por exemplo, também o foram. Vivemos sob uma chuva ininterrupta de imagens; os média todo poderosos não fazem outra coisa se não transformar o mundo em imagens, multiplicando numa fantasmagoria de jogos de espelhos - imagens que são destituídas de necessidade interna que deveria caracterizar todas as imagens como formas e como significados, como força de impasse a atenção, com riqueza de significados possíveis. (CALVINO, 1997).

Desta forma a fábrica da mentira gera segundo Salmon (2008), um Storytelling, ou seja, narrativas de histórias de vida (ações, sonhos, desejos de autonomia e atomização) que aparecem como elementos individualizantes e exemplares. O eu é ousado, criativo, inventivo e que assume os riscos e isso passa para a política na forma de um líder que se verticaliza e conta a sua storytelling como um indivíduo forte. $\mathrm{O}$ ator político representa um papel no sistema midiático. No entanto este mesmo Storytelling se apresenta como descontextualizado: reprimindo uma visão história (que una memória, história e política); e é espetacularizado: dos eventos e dos fatos mexendo com a linguagem: exasperada, não dialógica, emergencial, cheia de eufemismos e anacronismos. Esta forma de comunicação é vinculada através de uma hipercomunicação em redes e por Celulares. Segundo Vladimir Giachei (2011) o principal elemento neste sistema é a ligação entre economia, política e mídia, tendo a capacidade de ocultar os fatos e os acontecimentos. Ela se transforma em storytelling, manipulando a realidade.

\section{Conclusões}

O panorama acima mostrado não significa a expressão simples de uma realidade social fatalista, mas se resume na análise dos fatos que acorreram a partir da década de 1980, tendo suas nuances em aspectos culturais, políticos e econômicos anteriores. Nosso intuito é mostrar como as relações sociais se modificaram junto com as mudanças nas noções de espaço social e tempo histórico, globalização, cosmopolitismo, populismo e xenofobia. No entanto, este assunto tem relação direta com as questões territoriais, na medida em que envolve temas como: soberania nacional, delimitação do Estado Nação, mundo globalizado, não lugares e perda de referencias por indivíduos cada vez mais atomizados. Nosso trabalho 
apenas inicia uma discussão que tem por base o diagnóstico de uma conjuntura atual. Cabe então pensarmos, uma vez feitas as constatações, que rumos podemos indicar para os problemas aqui apresentados uma vez que fizeram de nossas reflexões.

\section{Referências}

AMSELLE, J. L. Les nouveaux rouges-bruns. Le racisme qui vient. Paris: Lignes, 2014.

AUGÉ, M. Não lugares: introdução a uma antropologia da sobremoderni-dade. $1^{\mathrm{a}}$ edição francesa. Lisboa: 90 Graus, 2005.

BAUMAN, Z. Archipiélago de excepciones. Buenos Aires: Katz Editores, 2005. . Medo Líquido. Rio de Janeiro: Zahar, 2008.

BASSO, P. Razzismo di Stato. Stati Uniti, Europa, Italia. Milano: Franco Angeli, 2011.

BECK, U. Disuguaglianza senza confini. Roma: Laterza, 2011(a). 2011(b).

Crónicas desde el mundo de la política interior global. Barcelona: Paidós,

Europa tedesca: La nuova geografia del potere. Roma: Laterza, 2013

. La mirada cosmopolita: o la guerra es la paz. Madrid: Paidós, 2005.

BECK, U. e BECK-GERSCHEIM, E. La individualización. El individualismo institucionalizado y sus consecuencias sociales e políticas. Barcelona: Paidós, 2003.

BODEI, R. Immaginare altre vite. Realtà, progetti, desideri. Milano: Feltrinelli, 2013.

BROWN, W. Stati murati, sovranità in declinio. Bari: Laterza, 2013.

Books, 2015

Undoing the Demos. Neoliberalism's Stealth Revolution. New York: Zone

BURGIO, A. Nonostante Auschwitz. Il "ritorno" del razzismo en Europa. Roma: Derive Approdi, 2010.

CALVINO, Ítalo. Seis propostas para o próximo milênio. São Paulo: Companhia das Letras, 1997.

FERRAJOLI, L. La democrazia attraverso i diritti. Roma: Laterza, 2013. Poteri selvaggi. Roma: Laterza, 2011.

GALLI, C. Political spaces and Global war. London: University of Minnesota Press, 2010.

GIACCHÉ, V. La fabbrica del falso. Strategie della menzogna nella politica contemporânea. Roma: Derive Approdi, 2011.

GREGOTTI, V. Architettura e postometropoli. Torino: Einaudi, 2011. 
KANT, I. A paz perpétua. São Paulo: L\&PM, 2008.

KEYNES, J. M. Teoria geral do emprego, do juro e da moeda. São Paulo: Relógio D’água, 2010.

HEGEL, G. W. F. Filosofia da História. Brasília: Editora UNB, 2008.

LE BOM. G. Psicologia das Multidões. São Paulo: Martins Fontes, 2016.

LOSURDO, D. La lotta di classe. Una storia politica e filosofica. Roma: Laterza, 2013.

MARX, Karl. Manuscritos econômico-filosóficos. Tradução de Jesus Ranieri. São Paulo: Boitempo, 2004.

. O Capital (Livro 1). Tradução: Rubens Enderle. São Paulo: Boitempo, 2013.

MASTROPAOLO, A. La democrazia è uma causa persa? Paradossi di un'invenzione imperfetta. Torino: Bollati Boringhieri, 2014.

NATOLI, S. Il buon uso del mondo. Agire nell'età del rischio. Milano: Mondadori, 2010.

RASPAIL, J. The camp of the saints. Éditions Robert Laffont, 1973.

RECALCATI, M. Il complexo di Telemaco. Genitori e figli dopo il tramonto del padre. 2015.

REYNIÉ, D. Les nouveaux populismes. Paris: Fayard/Pluriel, 2013.

RIVERA, A. Estranei e nemici. Bari: Derive-Approdi, 2003.

SALMON, C. Storytelling. La fabbrica dela storie. Roma: Fazi Editore, 2008.

SASSEN, S. Inmigrantes y ciudadanos: de las migraciones masivas a la Europa fortaleza. Madrid: Siglo XXI España, 2013.

. Expulsions: Brutality and Complexity in the Global Economy. Cambridge: Harvard University Press, 2014.

SARACENO, C. Coppie e famiglie. Non è uma questione di natura. Milano: Feltrinelli, 2012.

SCHMITT, K. Terra e Mar: breves reflexões sobre a história universal. São Paulo: 5 estrelas, 2008.

TODOROV, T. Muros caídos, muros erigidos. Buenos Aires: Katz, 2011.

Os inimigos íntimos da democracia. São Paulo: Companhia das Letras, 2012.

URBINATI, N. Democracy disfigured: Opinion, Truth and the People. London: Harvard University Press, 2014.

ZAGREBELSKY, G. Sulla lingua del tempo presente. Torino: Einaudi, 2010. 
RELACult - Revista Latino-Americana de Estudos em Cultura e Sociedade

Revista Latinoamericana de Estudios en Cultura y Sociedad | Latin American Journal of Studies in Culture and Society V. 03, ed. especial, dez., 2017, artigo $\mathrm{n}^{\circ}$ 581| relacult.claec.org |e-ISSN: 2525-7870

ZWEIG, S.. O mundo de ontem: recordações de um eiropeu. Rio de Janeiro: Zahar, 2014. 